\title{
(Re)Pensando o Crime como uma Relação de Antagonismo entre seus Autores e a Sociedade
}

(Re) thinking crime as a relation of antagonism among its actors and society

Karina Prates da Fonseca

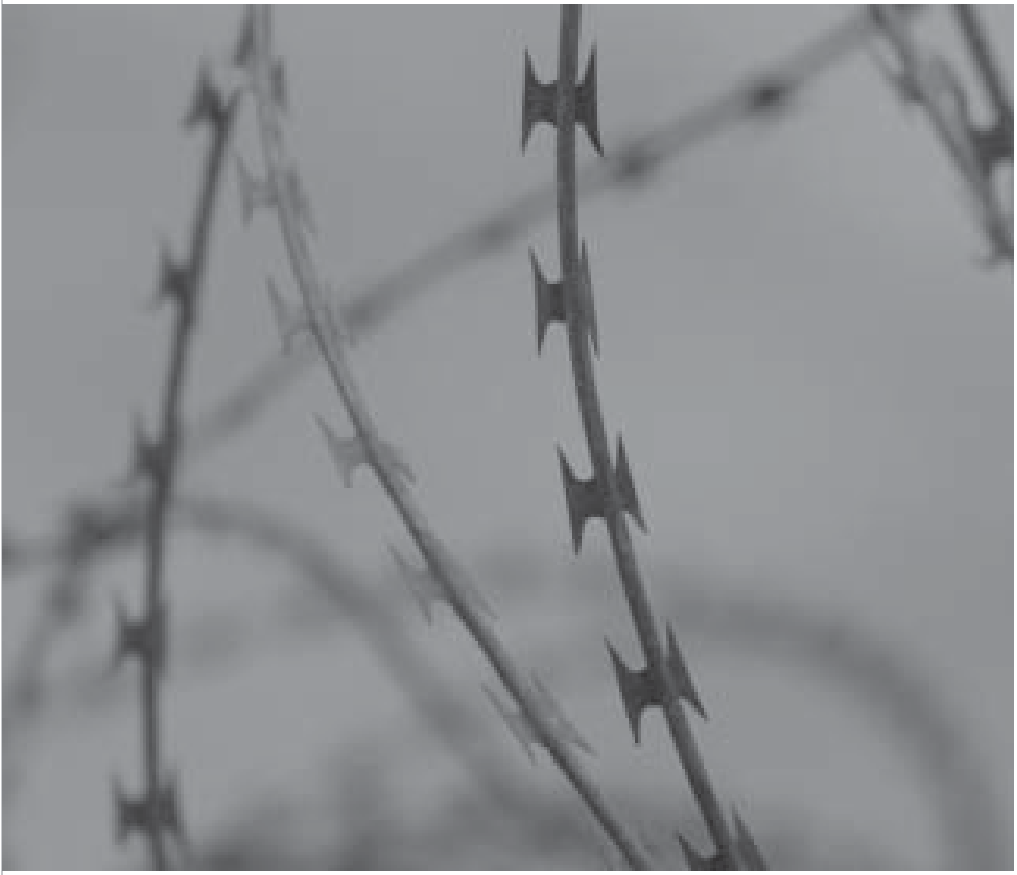




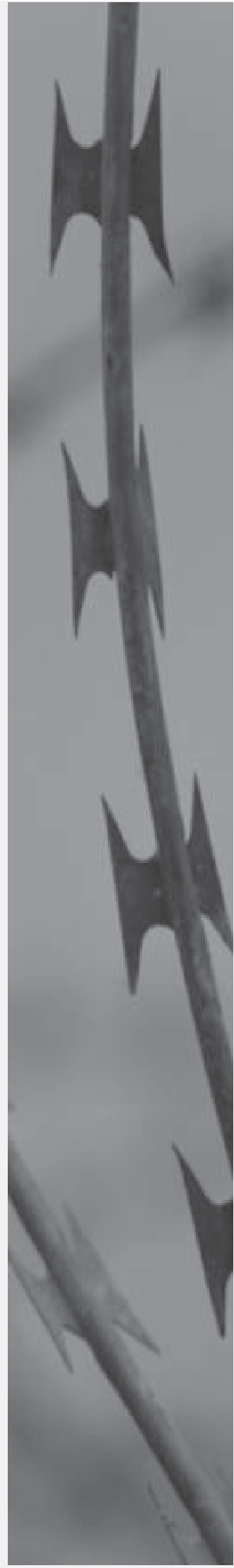

Resumo: Esta pesquisa está direcionada ao sistema penitenciário, à sociedade em geral e, especificamente, às reflexões sobre as práticas psi e aos desafios que se constituem nessa área de atuação segregada, tal qual sua clientela. Para tanto, fundamentou-se em estudos realizados sobre a história do sistema penitenciário e as relações nelas estabelecidas para responder às inquietações: O que é crime? Que relações se estabelecem entre seus atores e a sociedade? Quais os desafios dessa questão para a Psicologia? Dizer hoje que a pena da prisão e o cárcere, por si mesmos, não recuperam ninguém é, simplesmente, dizer o óbvio; igualmente, dizer que, no lugar de recuperar, degradam a pessoa do preso, não significa novidade alguma. Entretanto, nem sempre o que é óbvio para todos tem reflexos na prática, e essa é uma importante reflexão em tal estudo. Uma segunda, e talvez a mais significativa sugestão, é a de permeabilizar as muralhas institucionais, através da mobilização da sociedade civil, que assumiria sua parcela de responsabilidade e viabilizaria, assim, a reintegração social do preso, o grande desafio para a Psicologia. É imprescindível reconhecer as diferenças, principalmente para buscar soluções, mas também é imprescindível negar qualquer desigualdade, qualquer discriminação, quaisquer atos que colaborem para que o sentenciado - Ser Humano não consiga sua reintegração social.

Palavras-chave: crime, reintegração social, sociedade.

Abstract: This research is a theoretical study directed to the penitentiary system, to society in general and specifically to the reflections on psychological practice and the challenges that emerge in this area of segregated performance, as segregated as its clientele. For that purpose, this paper was based on studies carried on in the history of the penitentiary system and in the relatios there established to answer the question: What is crime? What relations does it establish among its actors and society? What are the challenges this issue brings for Psychology? Nowadays saying that the arrest penalty and the jail do not recuperate people is, simply to say what's obvious. Equally saying that instead of recuperating, they degrade the prisoner is not saying anything new. However, sometimes what's obvious for everyone is not reflected in daily life, and this is an important reflection in this paper. The second and perhaps the most meaningful suggestion is to make the institutional walls more flexible through the mobilization of society, that would assume its responsibility, thus making possible the social reintegration of the prisoner, the great challenge for Psychology. It is essential to recognize the differences mainly to find solutions, but it is also essential to deny any inequality, any prejudice and any acts that collaborate for that the sentenced person - a Human being - is not able to obtain his social reintegration.

Key words: crime, social reintegration, society. 
Segundo Foucault (1986), as primeiras formas de se castigar um criminoso eram através dos suplícios, da exibição pública da dor e do sofrimento. O criminoso era humilhado e torturado por meio de suporte legal e social:

Um fato é certo: em algumas dezenas de anos, desapareceu o corpo supliciado, esquartejado, amputado, marcado simbolicamente no rosto ou no ombro, exposto vivo ou morto, dado como espetáculo. Desapareceu o corpo como alvo

Sob o nome de crimes e delitos, são sempre julgados corretamente os objetos jurídicos definidos pelo Código. Porém, julgam-se também as paixões, os instintos, as anomalias, as enfermidades, as inadequações, os efeitos do meio ambiente ou da hereditariedade. Punem-se as agressões, mas, por meio delas, as agressividades, as violações e, ao mesmo tempo, as perversões, os assassinatos, que são, também, impulsos e desejos.

Foucault principal da repressão penal" Foucault (1977). Para esse autor, o lugar ocupado pela reforma da punição, a partir do século XVIII, foi colonizado pelos procedimentos disciplinares, que passaram a organizar o espaço social da mesma maneira que o saber jurídico teria sido colonizado pelas disciplinas.

O essencial passou a ser corrigir, reeducar e curar. Há mesmo aqueles que identificam a prisão com o hospital, o preso com o doente e a pena com o tratamento. O castigo, dirá Foucault (1977), passa da arte de causar sofrimentos insuportáveis a uma economia dos direitos suspensos.

Segundo esse autor, se não é mais ao corpo que se dirige a punição, em suas formas mais duras; sobre o que, então, aquela se exerce? A resposta dos teóricos - daqueles que abriram, por volta de 1760 , o período que ainda não se encerrou - é simples, quase evidente. Dir-se-ia inscrita na própria indagação, pois não é mais no corpo, e sim, na alma. À expiação que tripudia sobre o corpo, deve-se suceder um castigo que atue profundamente sobre o coração, o intelecto, a vontade, as disposições.

Esse autor esclarece que a alma à qual se refere não é uma ilusão ou entidade da teologia cristã. Ela tem uma realidade que é permanentemente produzida pelo poder que se exerce sobre aqueles que são fixados a um aparelho de produção e controlados durante toda a existência, ou seja, essa alma tem uma realidade histórica, que nasce de procedimentos disciplinares.

Sob o nome de crimes e delitos, são sempre julgados corretamente os objetos jurídicos definidos pelo Código. Porém, julgam-se também as paixões, os instintos, as anomalias, as enfermidades, as inadequações, os efeitos do meio ambiente ou da hereditariedade. Punem-se as agressões, mas, por meio delas, as agressividades, as violações e, ao mesmo tempo, as perversões, os assassinatos, que são, também, impulsos e desejos (Foucault, 1977). Segundo Thompsom (1980), a "prisionização" é um processo de aculturação. É a adoção, em maior ou menor grau, dos usos, costumes, hábito e cultura geral da prisão. Segundo o autor, todo encarcerado sofre, em alguma medida, tal processo, a começar pela perda de "status", ao se transformar, de um momento para o outro, "numa figura anônima de um grupo subordinado." Todo encarcerado sucumbe, de alguma maneira, à cultura da prisão, mesmo porque a cadeia é um sistema de poder totalitário formal, pelo qual o detento é controlado vinte e quatro horas por dia, sem alternativa de escape. Extramuros, o princípio é considerar lícito tudo o que não é expressamente interditado, enquanto, na cadeia, a lei é considerar proibido tudo o que não é expressamente autorizado.

A privação da liberdade por meio da detenção executa a lei jurídica, e, ao mesmo tempo, possibilita que se construa um saber clínico sobre os detentos. Para tanto, é necessário que o detento seja mantido sob um olhar de vigilância e observação, de segurança e saber, de totalização e individualização.

Não basta apenas aplicar as determinações judiciárias, é preciso que seja observado, no próprio detento, um saber que permita alterar a pena vigente conforme sua postura diante dos efeitos da detenção, conforme sua implicação com o processo de mudança e sua identificação com o crime cometido, ou seja, 
o efeito da reclusão sobre o detento é que deverá determinar o período de detenção, que poderá ser aumentado ou diminuido. Dessa forma, as punições e recompensas não são penas para fazer com que o sujeito respeite o regulamento existente para o funcionamento do sistema, mas teriam também a função de tornar efetiva a ação da prisão sobre os detentos, acarretando sua modificação e aceitação pela sociedade. Segundo Foucault (1986), "a prisão, peça essencial do conjunto das punições, marca certamente um momento importante na história da justiça penal: seu acesso à humanidade" (p.126) .

Por mais que seja uma estratégia de exclusão, isolamento e ajustamento do corrigir, as prisões mostram-se presentes ao interesse social apenas nos momentos em que sua rotina institucional é fortemente abalada, como nos casos específicos de rebeliões, motins, fugas e massacres, que são veiculados pelos meios de comunicação, e, a partir daí, incluídos no cotidiano "privado" das pessoas. Uma variada gama de sensações/sentimentos prolifera, configurando reações de repulsa, ódio, vingança, curiosidade, morbidez, compaixão e até solidariedade.

As instituições totais, como são chamadas por Goffman (2001), são caracterizadas por sua tendência ao fechamento, ao confinamento dos internos. Desde o momento da admissão, é construída uma barreira entre a relação social do interno e o mundo externo. A partir desse momento, inicia-se também o processo de mortificação do sujeito. Dentre as perdas, destacam-se a morte civil do sujeito e a morte do eu para a construção de um eu coletivo. A instituição prisão, por meio da punição pela privação de liberdade, não vai apenas punir o sujeito pelo crime cometido, mas pretende, em princípio, também modificá-lo, utilizando a disciplina como mecanismo.

No cerne do conceito de reabilitação penal, encontra-se a tarefa de transformar indivíduos criminosos em não criminosos, mas, em sua prática, a prisão é o corpo da exclusão, a segregação do indivíduo de dada sociedade, com o objetivo primeiro de mantê-lo, simplesmente, preso, segregado, longe dos "olhos sociais."

A partir do período imperial, tem início uma preocupação com a salubridade das prisões brasileiras, que são consideradas lugares sujos, insalubres, úmidos e fétidos. O Ministro da Justiça, em seu relatório datado de 19 de novembro de 1825, considera as prisões até então existentes "lugares imundos e impróprios para homens", e os presos, "vítimas que sofriam durante longos anos a nudez, a fome e a desesperança nos horrendos cárceres em que jaziam sepultados." Mas é no Segundo Reinado que tem início um pensamento de reforma, a partir da constatação de que as prisões em nada melhoraram. Vimos anteriormente, com Foucault, que as grandes reformas européias deslocaram o objeto da penalidade do corpo para a alma.

Pensando na execução da pena no Brasil, como fazer esse deslocamento da penalidade se os escravos (para melhor compreensão, esta autora sugere uma relação histórica entre os termos escravo-sentenciado-exclusão) e também, em certa medida, os desclassificados de todos os tipos, não apenas no período colonial como também no Império, não eram propriamente homens? Se os escravos não tinham alma? Para que as prisões se modificassem, no Brasil, era necessário, primeiro, reconhecer o escravo como homem; parece que o problema é atualmente absorvido na mesma "óptica social": o sentenciado é visto não como pessoa humana, mas como "criminoso", "ladrão", "bandido", portador de delito.

Reconhece-se que as prisões teriam que se modificar para se adequarem ao novo Código e adaptarem-se a isso que Foucault chama de tecnologias disciplinares. Esse tipo de poder, a disciplina, segundo a leitura foucaultiana, 
Não é apenas a ausência de cadeias limpas, seguras e arejadas o que se critica, mas uma lei branda, que respeita direitos demais, que serve não apenas para proteger a vida dos cidadãos honestos, mas também a dos ladrões,

dificultando sua condenação devido às novas exigências processuais. expande-se por toda a sociedade, assumindo as formas mais regionais e concretas. Há um investimento que toma a forma de técnica de dominação e possui uma tecnologia e história específicas; atinge o corpo do individuo, realizando um controle detalhado e minucioso sobre seus gestos, hábitos, atitudes, comportamento e discurso. É a massificação, despersonalização, mas é, ao mesmo tempo, a formação determinada de um saber técnico sobre esse indivíduo. É o interesse de Foucault pela formação do poder como produção de toda uma hierarquia que se realiza a partir da troca entre saberes disciplinares nas mais diversas instituições, sejam elas propriamente repressivas (como a prisão), econômicas ou até pedagógicas. O importante é buscar a produção de poder.

Nessa troca, o que caracteriza o conjunto hierárquico como vida é o poder difuso, e não o uso privado pelo topo da hierarquia; investe-se no conjunto sob a forma de análise para captar as resistências às cristalizações do poder.

Quando Foucault aborda, portanto, a produção de saberes baseada em determinadas práticas jurídicas como modelos de estabelecimento da verdade, substitui a conceituação jurídica de lei e as práticas ilegais pela correlação ilegalismoslei, deslocando, concomitantemente, aquela tradicional concepção do Direito para o campo da lei como substituto do poder, ao invés do princípio formulado pelo modelo monárquico, da lei como um poder único e centralizador, ou mesmo pelo ancoradouro histórico daqueles que querem obter e manter uma representação jurídica homogênea em toda a sociedade.

Do ponto de vista jurídico, o poder do Estado é exercido por meio das leis e do Direito, mas, segundo Foucault, as disciplinas se exercem por meio de regulamentos que expelem Direito, tornando-o mais minucioso e indulgente, uma verdadeira multiplicação dos procedimentos penais dentro de toda a sociedade; esses procedimentos não usam o discurso das leis, nem do Direito, mas formam, na verdade, um contradireito.

Assim é que tem lugar o início da construção da Casa de Correção da Corte, baseada no modelo Panopticon, que é um estabelecimento que introduz, no indivíduo, a consciência da vigilância constante. O indivíduo fica isolado e exposto ao olhar do outro, sem jamais vê-lo. Essa condição assegura o funcionamento automático do poder. $\mathrm{O}$ princípio é conhecido: na periferia, uma construção em anel; no centro, uma torre; esta é vazada, com largas janelas que se abrem sobre a face interna do anel; a construção periférica é dividida em celas, cada uma atravessando toda a espessura da construção; elas têm duas janelas, uma para o interior, correspondendo às janelas da torre, e a outra, que dá para o exterior, permite que a luz atravesse a cela de lado a lado. Basta, então, colocar um vigia na torre central, e, em cada cela, trancar um louco, um doente, um condenado, um operário ou um escolar (Foucault, 2000, pp.165 e 166). Esse estabelecimento funcionaria como laboratório do poder, que, através da coerção, de anotações e de estudos, procuraria transformar os indivíduos, através da delimitação entre o normal e anormal, ao estabelecer disciplinas individualizantes, experiências de modificação do comportamento.

Não é apenas a ausência de cadeias limpas, seguras e arejadas o que se critica, mas uma lei branda, que respeita direitos demais, que serve não apenas para proteger a vida dos cidadãos honestos, mas também a dos ladrões, dificultando sua condenação devido às novas exigências processuais. Assim, muitas vezes, a lei é contornada ou mesmo ignorada, quando se trata de prender e punir escravos, vadios e mendigos. Parece que a situação "criminalidade" tem uma conotação estigmatizada, socialmente acompanhada, se não "acoplada" à condição de pobreza, visto que a lei é uma gestão de ilegalismos 
permitidos a alguns - tornando-os possíveis ou inventando-os como privilégios das classes dominantes. Nesse sentido, proíbe, isola e toma outros ilegalismos não só como objeto, mas também como meio de dominação.

O papel do psicólogo, enquanto envolvido com o processo de acompanhamento e avaliação do sentenciado, está sendo revisto e reinventado. O procedimento formal e mecanicista do exame criminológico, marcado, sobretudo, por uma perspectiva legalista, oriunda do modus vivendi do universo jurídico -, o que divide, dessa maneira, a responsabilidade da punição e a repressão está sendo direcionado por um outro olhar o psicólogo como protagonista da sua própria atuação. O psicólogo deixa um lugar de trabalho pericial marcado pela subordinação aos magistrados para trabalhar em favor de seu saber técnico, ou seja, daquilo para o que foi contratado - direcionando seu olhar e a sua escuta aos conflitos subjacentes aos discursos manifestos, tanto pelo sujeito preso quanto pelos demais operadores jurídicos em ação, fazendo com que suas intervenções possam constituir-se em alteração de sentidos, que viriam a produzir um discurso mais criativo e libertador do que até então se produziu para atuar no processo de reintegração social do sujeito. Vislumbra-se uma nova postura, que se inicia pela sua própria atuação, aceitação dos sentenciados e, futuramente, de todos os agentes envolvidos no processo de reintegração social.

Esta se constitui na medida em que as muralhas são permeabilizadas por meio da atuação da sociedade, quando esta assume sua parcela de responsabilidade na problematização e, efetivamente, desenvolve ações "intramuros." A partir do momento em que acontece a possibilidade de um espaço para discussões/reflexões sobre o encarceramento, como a realização de concursos como esta Campanha Nacional dos Direitos Humanos, lançada no dia 10 de novembro de 2005, com o tema $O$ que foi feito para excluir não pode incluir, já acontece o processo em questão. Os objetivos da campanha são: identificar as práticas de Psicologia no sistema prisional e contribuir para as construções das atribuições, competências e possibilidades de formação do psicólogo no sistema prisional.

Recomenda-se a criação efetiva de parcerias, como a inédita, entre a Secretaria da Administração Penitenciária do Governo do Estado de São Paulo e as ONGs, que, segundo dados extraídos do sítio oficial da SAP (Secretaria de Estado da Administração Penitenciária), promoveram alteração positiva, nos dados do sistema prisional: os índices de reincidência permanecem baixíssimos, como também as ocorrências de fugas, sem contar a economia aos cofres públicos na manutenção do sentenciado, se comparada ao custo de um preso que habita uma unidade comum. O modelo de administração também é diferenciado: além da participação efetiva da comunidade, do Poder Judiciário, do Ministério Público e da Ordem dos Advogados do Brasil, na administração compartilhada, cabe à ONG proporcionar aos presos todas as formas de assistência (material, educacional, social, psicológica, da saúde, jurídica, religiosa e laboral), cabendo ao Estado a manutenção da segurança e da disciplina na unidade.

Na verdade, a intenção é otimizar tempo e recursos da "coisa pública", sendo que, por exemplo, para quaisquer compras, o Estado necessita da transparência burocrata das licitações; enfim, com as ONGs, não há necessidade alguma desses recursos burocráticos, pois as mesmas têm autonomia para suas ações.

Mas, para esta autora, mais importante que esses "dados percentuais", que, no seu entendimento, são em demasia prematuros (parece ser muito cedo para qualquer avaliação), é a questão que vem por trás de 
uma parceria entre o sistema penitenciário e as ONGs: a possibilidade de a sociedade civil adentrar os presídios, como dito acima, estreitando a relação intra-extramuros, bem como com as Universidades; por meio do trabalho do estagiário, o Conselho Federal de Psicologia poderia criar núcleos do CFP, talvez por meio das subsedes, com instituições de ensino, desde que notoriamente renomadas, nas quais seus alunos poderiam fazer $\mathrm{o}$ atendimento aos presos e seus familiares. Veja-se a Região do Vale do Paraíba, em São Paulo, onde se encontra um grande complexo penitenciário e, ao mesmo tempo, uma certa concentração de universidades; nesse mesmo centro, há um curso de Psicologia, onde alunas do quarto e do quinto ano se dedicam ao atendimento aos sentenciados, enfrentando os estigmas e preconceitos que efetivamente surgem (pois seus trabalhos são identificados com sua clientela) por prestarem contribuição, através de seus saberes e, notoriamente, por disputarem vagas em seleções no curso (no caso dos atendimentos em Psicologia) e, no caso da área de Educação, por empresas que se dedicam a contratações dos monitores (FUNAP), trabalho nos quais esta autora esteve inserida.

É importante que essa parceria entre as universidades se estenda até o trabalho voluntário, por meio das subsedes, como já dito, pois faz-se necessário um acompanhamento no sentido de evitar que essa intenção que, inicialmente, tem um caráter positivo e pertinente, desenvolva caráter de filantropia, o que vitimizaria o sentenciado e, dessa maneira, o excluiria novamente, reforçando sua condição.

O exame criminológico era realizado, no início da execução da sentença, com a finalidade de se obter o efeito, não só individual, mas individualizante, da pena na prisão.

Segundo Sá (1996), é "num momento em que, ao menos teoricamente, o condenado ainda não se contaminou com os efeitos perniciosos da vida carcerária e encontra-se temporalmente mais próximo de sua atividade criminosa, com que o diagnóstico criminológico tende a ser mais fidedigno, mais confiável, enquanto perícia."

Às comissões (corpo técnico, como explicado no art. 70) cabe a responsabilidade pela classificação e elaboração de um programa individualizador da pena, com vistas à reinserção social do encarcerado. A partir dele, deve acompanhar a execução da pena, sugerindo as progressões, regressões e conversões de regime, conforme a avaliação dos efeitos dos programas propostos ao apenado.

Da mesma forma que esses aspectos prescrevem as possibilidades para a realização de todas as atividades no interior das unidades, seus objetivos, igualmente, intervêm decisivamente nos pereceres da comissão.

A seguir, será feita a análise de alguns artigos da LEP - Lei de Execução Penal (Lei no7210/84):

Art. 5‥ - Os condenados serão classificados segundo os seus antecedentes e personalidades, para orientar a individualização da pena. A individualização da pena é uma das chamadas garantias repressivas, constituindo postulado básico da Justiça. Individualizar a pena na execução consiste em dar ao sentenciado as oportunidades e os elementos necessários para lograr a sua reinserção social, posto que é pessoa e ser distinto.

Art. 60 - A classificação será feita por comissão técnica de classificação que elaborará o programa individualizador da pena.

Art. 7o - A comissão técnica de classificação, existente em cada estabelecimento, será presidida pelo diretor e composta, no mínimo, por dois chefes de serviço, um psiquiatra, um psicólogo e um assistente social, quando se 
tratar de condenado à pena privativa de liberdade. Remete-se diretamente à gestão da pena, com fins de classificação e individualização. Não possui por finalidade a questão jurídica, a informação sobre a dinâmica do ato criminoso, e não visa a elementos de prova ou introdutórios do processo.

Art. 8o - O condenado ao cumprimento de pena privativa de liberdade, em regime fechado, será submetido a exame criminológico para obtenção dos elementos necessários a uma adequada classificação e com vistas à individualização da execução.

Art. $9^{\circ}$-A comissão, no exame para obtenção de dados relevantes da personalidade, observando a ética profissional e tendo sempre presentes peças ou informações do processo, poderá:

\section{I-Entrevistar pessoas;}

II-Requisitar, de repartições ou estabelecimentos privados, dados e informações a respeito do condenado.

No sistema penitenciário do Estado de São Paulo, em suas formas de gestão e em sua cultura organizacional, os pareceres da comissão técnica de classificação se inseriam de modo indelével nos aspectos de contenção e controle da massa carcerária; hoje, o parecer dos técnicos não representa mais poder de interferência nas progressões de regime, e sim, na conduta do próprio indivíduo.

Tal procedimento deveria ser utilizado nos centros de detenção provisória, logo após a condenação, com o intuito de definir a qual penitenciária esse sentenciado será encaminhado para o cumprimento da pena imposta. No Estado de São Paulo, já existem várias penitenciárias destinadas a um perfil determinado de condenado.
O trabalho em unidade prisional, enquanto instrumento de reintegração social, é um processo dinâmico; os profissionais, ao realizarem suas diferentes funções, precisam estar conscientes do seu papel de agente transformador da sociedade e ter uma visão humanizada do sentenciado.

A constituição dos direitos e deveres relativos à pessoa que está em cumprimento de pena encontra-se na perspectiva da efetivação da execução penal. O Estado, ao assumir a tutela do indivíduo preso, deve garantir reais condições para o Direito, através das quais procura garantir a convivência sem conflitos e o respeito entre os reintegrados e com as outras pessoas com as quais eles se relacionam.

De acordo com a Lei de Execução Penal (LEP), em seu art. 1으, a execução penal tem por objetivo, além de efetivar as disposições de sentença ou decisão criminal, "propiciar condições para a harmônica integração social do condenado."

O interessante é pensar ainda ações de execução da pena, como ressalta o artigo 4 o da LEP, em todas as suas fases: no aspecto socioeducativo, através de palestras e debates para as produções, por meio de cursos de capacitação e troca de experiências, e na comercialização, que acontecerá via conselhos da comunidade, organismos estatais e instituições comunitárias, bem como com a sociedade civil organizada (ONGs).

Prossegue a referida Lei, determinando, no art. 5으, que os sentenciados deverão ser classificados segundo os seus antecedentes e personalidade, para orientar a individualização da execução penal. Dessa forma, o delito não deve ser compreendido apenas como um comportamento antijurídico, que desencadeia a inexorável pretensão punitiva estatal, ou mesmo como um fenômeno patológico "alheio" ao sistema que deve ter drástica erradicação, mas sim, como um problema social, que pressupõe antecedentes históricos 
Os "criminosos" são membros da sociedade e representam um segmento social, portanto, atuam de acordo com conflitos e impulsos arraigados nessa mesma sociedade. e socioculturais que pré-determinaram perfis humanos. Os "criminosos" são membros da sociedade e representam um segmento social, portanto, atuam de acordo com conflitos e impulsos arraigados nessa mesma sociedade. É interessante salientar ainda, em seu artigo 28, que "o trabalho do condenado, como dever social e condição de dignidade humana, terá a finalidade educativa e produtiva." Assim sendo, e considerando-se a necessidade inerente ao homem de desempenhar atividades que o dignifiquem e impeçam o ócio, e visando, ainda, a proporcionar condições para a própria manutenção e direcionamento da energia vital, urge, em se tratando de sentenciados, propiciar um espaço para reflexão, posicionamento e conscientização do valor do trabalho desenvolvido nos vários setores da unidade prisional.

Além disso, considerando-se que o trabalho extramuros prepara o sentenciado para a progressão de regime e posterior liberdade, viabilizando a reintegração social, o que se visa é à orientação sobre sua importância para a vida do sentenciado; enquanto aprisionado, é "instrumento/recurso" para melhor lidar com as dificuldades e propiciar a criação de estratégias que possibilitem a integração ao trabalho, o que positivaria sua adaptação quando do reingresso social e ao seio familiar. É interessante pensar no trabalho como um canal de comunicação entre o sentenciado e a comunidade, comunicação essa que abrange não só a esfera de expressão, ou seja, a produção, mas também a linguagem da dinâmica econômica, através da comercialização.

Segundo Baratta (1990), pretende-se, através do trabalho, reconstruir formas de diálogo entre o "cárcere e a sociedade, nas quais os sentenciados reconheçam a sociedade externa, e a sociedade externa se reconheça no cárcere."

Conforme dispõe o art. 31 da Lei de Execução Penal, "o condenado à pena privativa de liberdade está obrigado ao trabalho na medida de suas aptidões e capacidade." O reintegrado deve trabalhar levando-se em conta, evidentemente, suas condições físicas, mentais, intelectuais e profissionais, o que tem como finalidade a sua reinserção na sociedade.

Ainda segundo Baratta (1990), qualquer iniciativa que torne menos dolorosa e danosa a vida na prisão, ainda que seja para guardar o preso, deve ser encarada com seriedade quando realmente for inspirada no interesse pelos direitos e destino das pessoas detidas e proporcionar uma mudança radical e humanista, e não um reformismo tecnocrata. Segundo Sá (1998), o trabalho deve ser encarado como um fator importante na formação e na vida de qualquer ser humano. As atividades laborativas devem estar associadas ao mercado de trabalho e devem preparar profissionais atualizados com os avanços tecnológicos, pois de nada adianta desenvolver atividades para as quais não haja mercado externo, exceto nos casos de laborterapia regulada por prescrição médica. A formação profissional e o trabalho penitenciário devem propiciar ao reintegrando maiores oportunidades de inserção no mercado de trabalho, para que ele possa manter-se financeiramente e restabelecer sua relação com a sociedade.

Presente desde os primórdios da prisão, a educação é arrolada como atividade que visa a proporcionar a reabilitação dos indivíduos punidos. Contudo, considerando que os programas de operação penitenciária se apresentam de forma premente a fim de adaptar os indivíduos às normas, procedimentos e valores do cárcere afiançando, portanto, aquilo que se tornou o fim precípuo da organização penitenciária: a manutenção da ordem interna e o controle da massa carcerária - o enfoque principal foi anulado: autonomia para um aprendizado eficaz - quais são as possibilidades de uma "educação autêntica, que não descuide da vocação 
ontológica do homem, a de ser sujeito?" (Freire,1979).

No interior das prisões, a contradição do processo de ajustamento materializa-se nas possibilidades concretas de os indivíduos punidos se preservarem como sujeitos, na resistência a subjugarem-se plenamente aos valores da instituição e do sistema social que Ihes é inerente. A característica fundamental da pedagogia do educador em presídios é a contradição, é saber lidar com conflitos, é tentar a inclusão em um contexto de exclusão. A educação, dentro do sistema prisional, tem dificuldades relevantes e concretas; uma delas é a rotatividade da população carcerária entre as unidades do sistema prisional. As atividades identificáveis com a área da reabilitação educação, recreação, esportes, biblioteca, cursos em geral - assumem uma posição secundária, se comparadas ao sistema de controle da prisão, cuja prioridade é fazer com que o encarcerado aprenda a ter complacência com as autoridades e com os regulamentos penais.

O dilema punir e reintegrar tende a se dissipar, cedendo lugar à complementaridade. A rigor, portanto, não existe propriamente, na gestão penitenciária, uma contradição entre ambos os aspectos, que convergem seus procedimentos e orientações ao fim de socializar os indivíduos punidos com a disciplina do cárcere, com os códigos que compõem esse sistema social. Não pode haver mudança se não houver, paralelamente, um processo significativo de educação, entendida como um processo de busca da própria identidade, pessoal e grupal, que fuja completamente das propostas carcerárias.

$\mathrm{Na}$ educação de jovens e adultos, principalmente dentro do sistema penal, que possui normas e procedimentos próprios, é fundamental fazer a leitura da realidade para transformá-la em atitudes concretas, respeitando os educandos e educadores e promovendo processos que possibilitem autonomia e competência. Dessa forma, a ação educativa deve resultar na melhoria da qualidade de vida, aspecto crucial para a redução dos índices de criminalidade. Em termos exatos, a atuação da instituição deve trazer reflexos para a vida desses homens e possibilitar condições de (re)inserção social pela elevação de escolaridade adquirida ainda no período de privação de liberdade.

Se, por um lado, é difícil definir o grau de intensidade de sofrimento que pode ser infligido a alguém sob a justificativa de que tal aplicação de sofrimento se deve à atribuição de uma pena estabelecida pelo ordenamento jurídico vigente, por outro lado, há o problema daquilo que se convencionou chamar direitos humanos.

A história dos DUDH é a história da Ética, e hoje as instâncias éticas se organizam prescindindo de qualquer instância transcendente (tal como na época de Sócrates, Platão, Aristóteles, Agostinho e Tomás de Aquino), restringindo-se ao espaço da imanência e ao discurso que busca um consenso entre os interlocutores. Como resultado desse horizonte epistêmico, que se assenta não sobre os fundamentos transcendentes de um Deus descoberto pela razão (como fizeram os gregos) ou pela revelação (como fizeram os cristãos), mas sobre os fundamentos imanentes da discussão que busca o consenso e a livre adesão, apresentam-se à humanidade os DUDH, cuja fórmula pétrea é a Declaração Universal dos Direitos Humanos.

É apenas a partir dessa construção intelectual que se encontra hoje um fundamento para a proposição de quaisquer direitos que possam ser definidos com uma perspectiva universalizante que alcance a envergadura de todos os povos que vivem sobre o Planeta. Portanto, é a partir de uma declaração elaborada através da discussão que se busca um critério de ação e de organização da sociedade 
mundial. Partindo, pois, da Declaração Universal dos Direitos Humanos, a ONU apresenta conceitos e indicadores que sirvam de norte para a ação das mais diversas entidades, em que os mais variados escopos sejam, de alguma forma, orientados por padrões éticos e sustentáveis de atuação. É óbvio que não há nada que dê a essa instância da ONU um estatuto de infabilidade. Todavia, a ação da ONU e a produção de seu staff de intelectuais tem se mostrado de uma sensatez e de uma lucidez única, que devem servir de farol para a humanidade, que se encontra perplexa e muitas vezes como que à deriva, sem saber exatamente como proceder diante de problemas tão complexos como os que se apresentam ao homem hodierno.

Nesse contexto de constituição de direitos humanos, há a resolução $n^{\circ} 43 / 173$, da Assembléia Geral, de nove de novembro de 1988, elaborada pela ONU, a saber "Conjunto de princípios para a proteção de todas as pessoas sujeitas a qualquer forma de detenção ou prisão" - constituída por trinta e nove princípios que indicam como tratar aqueles que estejam submetidos a qualquer forma de detenção ou prisão. Há outros dois documentos prolatados pela Assembléia Geral da ONU, que foram adotados pelo primeiro Congresso das Nações Unidas para a Prevenção do Crime e o Tratamento de Delinqüentes. O primeiro documento chamase Princípios Básicos Relativos ao Tratamento de Reclusos, e o segundo documento chamase Regras Mínimas para o Tratamento de Prisioneiros, no qual há noventa e cinco parágrafos acompanhados de treze procedimentos comentados.

Cabe ressaltar um aspecto, particularmente dramático, do caráter perverso da pena de prisão. O Estado, ao decretar, através da sentença do juiz, a pena de prisão, explicita, formaliza e consagra uma relação de antagonismo entre o condenado e a sociedade. As conseqüências desse caráter perverso da pena da prisão podem chegar a ser profundamente drásticas para a mente e para a vida do detento. Sua "recuperação" deverá ser uma recuperação para a sociedade, ou seja, será uma reintegração social e só será possível mediante a resolução desse antagonismo e a superação desse confronto. Por um lado, portanto, a pena da prisão traz, como conseqüência, o recrudescimento do confronto e do antagonismo entre preso e a sociedade, por outro lado, a reintegração social do preso só será viável mediante a participação efetiva, tecnicamente planejada e assistida, da comunidade.

Podem-se classificar os graves problemas carcerários em dois grandes grupos. O primeiro são os problemas decorrentes da má gestão da coisa pública, falta de interesse político, inabilidade administrativa e técnica. Entre os incontáveis e sobejamente conhecidos problemas desse grupo, situam-se os seguintes: presídios sem a infra-estrutura mínima necessária, material e humana, para o cumprimento de pena; falta de condições materiais e humanas para o incremento dos regimes progressivos de cumprimento de pena, conforme prevê o texto legal; superpopulação carcerária, com todas as inúmeras conseqüências; descumprimento da lei, etc. Poder-se-ia mencionar, ainda, a falta de pessoal administrativo, de segurança e disciplina, e pessoal técnico formado e habilitado para a função. Entretanto, o problema parece situarse em outro âmbito. O que existe é a falta de pessoal realmente "vocacionado".

Scheneider (1991) aborda com propriedade essa questão. A falta de pessoal vocacionado se deve ao profundo desprestígio dessa área profissional e ao desprestígio do cárcere, desprestígio fomentado tanto por parte dos órgãos oficiais como por parte da sociedade, que, ao se afastar da problemática carcerária, de certa forma isola o profissional que executa suas funções junto ao sistema prisional, apontando-o como parte da existência daquilo 
que a própria sociedade deseja anular, por tratar-se de uma vergonha e de um problema com o qual não consegue lidar, o que se torna algo comprobatório de sua fragilidade.

O segundo grupo são os problemas inerentes à própria natureza da pena privativa de liberdade, em especial quando cumprida em regime fechado, e os inerentes à própria natureza do cárcere. Entre eles, situam-se: o isolamento do preso em relação a sua família, a sua segregação em relação à sociedade, a convivência forçada no meio delinqüente, o sistema de poder (que controla todos os atos do indivíduo), as relações contraditórias e ambivalentes entre o pessoal penitenciário e os presos (o pessoal oferece-lhes apoio e assistência, e, ao mesmo tempo, os contém, os reprime e os pune).

A grande diferença entre o segundo e o primeiro grupo é que seus problemas são, praticamente, inevitáveis; é impossível desenvolver em alguém a maturidade para o convívio em sociedade segregando-o da sociedade.

Ora, no cerne dos problemas do segundo grupo, daqueles que são inerentes à própria natureza do ambiente carcerário, está o aprisionamento.

Segundo Castro (1990), "ninguém aprende a viver em liberdade sem liberdade." Entretanto, no lugar de se pregar, pura e simplesmente, a falência do sistema prisional, há que se exigir e buscar o encaminhamento de soluções dos problemas do primeiro grupo, de um lado, e de outro, buscar formas de se minorarem os problemas do segundo grupo.

Como já especificado, nenhum ser humano normal aceita, naturalmente, um poder totalitário que o controle vinte e quatro horas por dia, daí emergirem, entre os presos, um poder informal e uma cultura paralela, que define regras, costumes, uma ética própria e até mesmo critérios e condições de felicidade e sobrevivência próprias. Não é descabido se conjeturar sobre um pacto latente (não verbalizado) entre esses dois sistemas de poder, a fim de se garantir a tranqüilidade, ainda que aparente, perante a sociedade e a opinião pública, da instituição prisional. Constitui-se, pois, assim, um ambiente artificial, do qual ninguém gosta, num primeiro momento, mas aos quais todos, com o tempo, acabam aderindo, de uma forma ou de outra. Dessa adesão, surge o aprisionamento, que pode atingir não só os presos como também a direção, os agentes penitenciários e, quem sabe, os próprios técnicos. A partir do momento em que o técnico se deixa levar pela rotina e passa a exercer, indiscriminadamente, seu poder de opinar, esquecendo-se de que o preso é uma pessoa, esse técnico já está se "prisionando." O diretor, segundo Thompson (1980), dá seu primeiro passo rumo ao aprisionamento, quando, em que pese todo seu idealismo inicial, se deixa levar, perante o eterno conflito regeneração $x$ segurança, pelo princípio latente de que a "regeneração" pode falhar, mas a segurança... Essa jamais!

A vida carcerária é vida em massa, sobretudo para os presos, evidentemente. Como conseqüência, ela acarreta uma verdadeira desorganização da personalidade, ingrediente central do processo de aprisionamento. Entre os efeitos do aprisionamento, que marcam, profundamente, essa desorganização da personalidade, cumpre destacar: a perda da identidade e a aquisição de nova identidade, o sentimento de inferioridade, o empobrecimento psíquico, a infantilização e a regressão. O empobrecimento psíquico acarreta, entre outras coisas, o estreitamento do horizonte psicológico, a pobreza de experiências, as dificuldades de elaboração de planos a médio e longo prazos. A infantilização e a regressão manifestam-se, entre outras coisas, através de dependência, busca de proteção, busca de soluções fáceis, projeção
A vida carcerária é vida em massa, sobretudo para os presos, evidentemente. como conseqüência, ela acarreta uma verdadeira desorganização da personalidade, ingrediente central do processo de aprisionamento. 
da culpa no outro e dificuldade de elaboração de planos.

Segundo Baratta (1990), o melhor cárcere é aquele que não existe, e o cárcere será melhor quanto menos cárcere for. Portanto, se, por um lado, a pena da prisão e o cárcere são males necessários, por outro lado, isso não nos autoriza a nos acomodarmos, mas, pelo contrário, adverte-nos da necessidade de estarmos continuamente conscientes de que o cárcere, na medida do possível, deve tornarse sempre menos cárcere, através de complexas estratégias de individualização da execução da pena (que não consistem, unicamente, na progressão da pena), cuja política, necessariamente, se choca com a política de enrijecimento da segurança. Ainda que a segurança se imponha, nunca podemos nos esquecer de que ela é um pólo de preocupação, que se opõe, claramente, à política de individualização da execução.

Segundo Zafforini (1998), os presos, em sua maioria, são pessoas que, mais que exploradas pelo sistema capitalista, foram excluídas por ele, tornaram-se vulneráveis perante o sistema punitivo e por este foram selecionadas, com o que sua vulnerabilidade se agravou mais ainda. Dever-se-á ter sempre presente a idéia de que o crime, embora se constitua, na maioria das vezes, num ato anti-social, pois, a uma conduta que foi definida pelo Direito Penal como criminosa, há outras condutas, às vezes muito mais prejudiciais à sociedade, que não foram igualmente definidas como crime por esse mesmo Direito Penal, estando seus autores isentos de qualquer pena e vivendo na sociedade como pessoas de bem. É sempre bom que tais reflexões estejam presentes na mente e no trabalho dos profissionais do sistema penitenciário, para que tenham consciência da complexa realidade humana e social daqueles que estão sob seus cuidados, sobre como devem conceber o tal caminho de "volta" ou a tal "readequação ética" para os mesmos.
Se, nas bases conceituais, não adotamos o conceito tradicional de criminologia clínica, também não podemos aceitar, sem restrições, os termos "tratamento", "recuperação" do preso e outros equivalentes, dada a clara conotação dos mesmos e de que a chamada conduta criminosa seja expressão de algum desajuste ou desvio de conduta por parte do seu ator. Eles não se ajustam aos posicionamentos propostos, pois fazem supor que é sempre o preso que deve se "modificar', deve se "adequar", já que, conforme deixam a entender, não só a responsabilidade do crime cometido como também a "culpa" é toda e somente dele. Ora, se pelo conceito moderno de criminologia clínica essa concepção já não é mais aceita tão tranqüilamente, muito menos ela é aceita se se levar em conta o conceito crítico, que, embora não seja integralmente adotado, até por uma questão de praticidade e visão realista de nosso atual momento, não deixa de estar presente em nossas reflexões, e, conforme foi dito acima, de suscitar, em nós, a necessidade de ter sempre nossa consciência voltada para certos aspectos polêmicos do que seja crime, homem criminoso, da assim chamada "motivação criminal" e da própria lei penal. O crime, além de ser de natureza definitorial, isto é, uma conduta selecionada e tipificada pelo Direito Penal, é, na maioria das vezes, expressão de uma relação de antagonismo entre seu ator e a sociedade, antagonismo esse que tem início na infância.

Assim, num momento em que está sendo feita uma reflexão das bases conceituais de um sistema penitenciário, faz-se mister especificar e ressaltar alguns aspectos, sob a óptica psicológica, dessa degradação da pessoa do preso, decorrente da pena de prisão e da vida carcerária (efeitos de aprisionamento). A partir da conscientização dessa degradação, decorre a conscientização da responsabilidade da sociedade no complexo problema da reintegração social do preso. 
Noutros termos, o crime é expressão de uma história de conflitos (Sá, 2001). Ora, a "resolução", a superação de uma relação antagônica supõe que uma das partes tenha sido banida, tenha sido excluída; a resolução supõe, necessariamente, a superação dessa exclusão e a retomada de diálogo, ou seja, a, assim chamada "ressocialização" do preso, na verdade, deveria ser chamada de reintegração social do preso, sobretudo por parte da sociedade. Pela reintegração social, a sociedade (re)inclui aqueles que ela excluiu através de estratégias nas quais esses "excluídos" tenham uma participação ativa, não como meros "objetos de assistência", mas como sujeitos. O termo reintegração social é proposto por Baratta (1990) em oposição a termos como "reabilitação" e "ressocialização", exatamente pela responsabilidade da sociedade nesse processo, por subentender que o preso é compreendido como alguém exatamente igual a todos os demais homens livres, deles se diferenciando unicamente por sua condição de preso e de segregado.

Baratta (1990) aborda essa questão da segregação social do preso, que já sofrera anteriormente, ao longo de sua vida, a marginalização que o autor chama de primária. Quando preso, passou a sofrer a marginalização secundária, cabendo à sociedade preocupar-se diretamente para minorar os efeitos dessa marginalização, assim evitando o retorno do ex-presidiário à marginalização primária, pois, caso contrário, a marginalização secundária facilitaria o retorno à primária, daí à prática de novos crimes e, por fim, o retorno ao cárcere.

Segundo Ferreira (apud Fazenda, 1997), a interdisciplinaridade é a visão integral do fenômeno, do mundo, do ser, do próprio homem, portanto, seria a visão integral do fenômeno "crime", do mundo da prisão e do homem encarcerado. Visão integral não quer dizer, simplesmente, visão do "todo", mas visão dos fenômenos sob as diferentes óticas.
A administração carcerária, conforme comumente se constata, é orientada prioritariamente no sentido da segurança e disciplina. Pois bem, uma administração orientada nos termos acima carece de uma qualidade fundamental: a interdisciplinaridade. Cabe, de início, dizer que gestão prisional, na medida em que se torna interdisciplinar, não é função de uma pessoa... de um diretor. Ao contrário, dever-se-ia distribuir os profissionais em uma rede e incluir um complexo de atividades sustentadas por uma complexidade de conhecimentos técnico-científicos e, ao mesmo tempo, por sentimentos, atitudes e modos de ação que sempre estão a demandar uma rede de atores interdependentes.

Dizer hoje que a pena de prisão e o cárcere, por si mesmos, não recuperam ninguém é, simplesmente, dizer o óbvio. Igualmente, dizer que, no lugar de "recuperar", a pena da prisão e o cárcere degradam a pessoa do preso não significa hoje dizer novidade alguma. Entretanto, nem sempre o que é óbvio para todos tem reflexos na prática, ao menos da forma como deveria ter. Nem sempre o fato de ser óbvio garante que se tenha, sobre a referida "verdade", uma consciência necessária, uma consciência que seja transformadora.

A partir da conscientização da responsabilidade da sociedade no complexo problema da reintegração social do preso, a autora pensa ser este o momento em que o profissional psicólogo deve atuar efetivamente dentro do sistema, trazer sua contribuição por meio do seu saber, na relevante questão em tese; a reintegração social é o grande desafio para a Psicologia.

Considerando que o CFP se encontra afinado com essa perspectiva de alinhamento e realinhamento global e internacional com a problematização, a saber - sistema prisional, encarceramento e subjetividade: desafios para a Psicologia -, essa conclusão aponta sugestões de parcerias e consórcios entre as 
universidades e a sociedade civil organizada, daí a importância da iniciativa desse órgão na criação de fóruns que proponham, de forma criativa, soluções para os grandes problemas nacionais em relação ao sistema penitenciário e, mais particularmente, à atuação desse profissional, que traz consigo, tal qual sua clientela, o reflexo da opinião pública e suas representações.

É muito significativo que o esforço para pensar "todos" os problemas no sistema penitenciário esteja em conexão direta com as proposições humanitárias e humanizantes da ONU. Certamente esse é o primeiro passo a ser dado por aqueles que queiram refletir seriamente sobre esse problema e que queiram atuar de forma significativa - a autora pensa que o psicólogo deve estar enquadrado e enraizado nessa perspectiva - para que um dia o diário da ONU relativo às condições penitenciárias possa vir a ser efetivo no Brasil. Portanto, essa sintonia existente entre os princípios da ONU e as orientações brasileiras, emitidas pelo CNPCP na sua Resolução sobre as regras mínimas, é de absoluta importância, pois fornece a direção do caminho que deve ser seguido.

Em segundo lugar, é necessário que o esforço para se pensar o problema da atuação do psicólogo na problemática prisional seja dividido com outras parcerias, ou seja, é possível realizar uma terceirização desse esforço. É interessante ver como certas agências das Nações Unidas trabalham. A UNESCO, por exemplo, convida especialistas para participar de um fórum que não tem custo de inscrição. O convidado paga apenas suas passagens e sua hospedagem. $\mathrm{O}$ custo do evento é pago pela UNESCO.

Uma terceira indicação mais pontual, diretamente ligada à anterior, aponta a necessidade de elaboração de formas criativas de envolvimento de pessoas que possam entrar em contato com o sistema penitenciário. Uma situação pragmática é a de alunos e alunas dos cursos de Psicologia e de Direito que fazem seus estágios atendendo presos e seus familiares nas instalações dos presídios; além de estarem efetivamente participando do processo de reintegração social desse sentenciado, o estagiário chega com "sangue novo", com desejo de aprender e, em conseqüência, de realizar uma ação transformadora positiva. Esses alunos contam com a supervisão de professores doutores, especializados em Psicologia jurídica.

Uma quarta sugestão, que entra como outra maneira de fomentar esta reflexão tão profícua, seria o fornecimento de bolsas de estudos para projetos de estudantes universitários que queiram se dispor a fazer atendimentos aos presos; dessa maneira, há possibilidade de um investimento cultural extramuros e uma efetiva ação profissional intramuros, concretizando, assim, uma ação transformadora de "mão dupla".

A quinta sugestão seria o fomento de bolsa de mestrado e doutorado em parceria com agências nacionais e estaduais de pesquisa (CNPq, CAPES, etc).

Segue-se uma sugestão de caráter mais significativo, orgânico e de constituição mais complexa e que é inter-relacionada: a propositura de concursos, não só de monografias, mas concursos de projetos, nos quais os participantes seriam grupos constituídos por alunos de Direito, de Psicologia e Serviço Social, acompanhados por professores e com o aval da instituição, que cederia suas instalações, concretizando, assim, uma equipe de estudos interdisciplinar, formatada no referencial teórico apresentado neste trabalho.

Considerando tais reflexões, a autora entende que é possível vislumbrar um Brasil onde o atendimento à pessoa humana do preso pode alcançar a máxima amplitude, demonstrando, assim, um desenvolvimento civilizatório e deixando para trás o presente como um distante e remoto passado ao considerar essa desumanidade instaurada no mínimo, como bárbara! 


\section{Karina Prates da Fonseca}

Bacharel em Psicologia pela Universidade Salesiana de São Paulo -Unidade Educacional de Lorena. Rua dos Andradas, no 214, ap. B - Centro. Pindamonhangaba - São Paulo. Tel: (12) 36488685 Cel: (12) 81159762 E-mails: kp.fonseca@hotmail.com - kpfonseca@bol.com.br

ADORNO, S. A Prisão sob a Óptica de seus Protagonistas. Revista de Sociologia da USP. São Paulo, vol. 3, no 1 e no 2, pp.7-40, 1991.

ALBUQUERQUE, J. A. G. Métodos da Desordem. São Paulo: Paze Terra , 1978.

ALTOÉ, S. Menores em Tempo de Maioridade: do Internato-prisão à Vida Social. Rio de Janeiro: Universidade Santa Úrsula, 1993.

ANCONA-LOEZ, M. Psiodiagnóstico: Processo de Intervenção. São Paulo: Cortez, 1995.

AUGUSTO, A.S. Reincidência Criminal sob o Enfoque da Psicologia Clínica Preventiva. São Paulo: Ed. Pedagógica e Universitária, 1997.

BARATTA, A. Por un Conjunto Crítico de Reintegración Social de Condenado. In: Oliveira, E. (coord.) Criminologia Crítica. Fórum Internacional de Criminologia Critica, Belém: CEJU, pp.141-157, 1990.

BRITO, L. M. T (org). Temas de Psicologia Jurídica. Rio de Janeiro: Relume Dumará, 1999.

\section{CAPEZ, F. Curso de Direito Penal. São Paulo: Saraiva, 2003.}

CASTRO, M. M .P. Ciranda do Medo - Controle e Dominação no Cotidiano da Prisão. Revista USP, São Paulo, março-abril-maio 1991.

FISCHER, R.S. O Círculo do Poder - as Práticas Invisíveis de Sujeitação nas Organizações Complexas. In: Fleury, M.T.L. e Fischer, R.S. (org). Cultura e Poder nas Organizações. $2^{a}$ ed. São Paulo: Atlas, 1996.

FISCHER, R.S.; ADORNO, S. Análise do Sistema Penitenciário do Estado de São Paulo: o Gerenciamento da Marginalidade Social. São Paulo: Cedec, Relatório de Pesquisa, 1987.

Políticas Penitenciárias: um Fracasso. Lua Nova- Cultura e Política, no 34, São Paulo, pp.70 - 79, abriljunho-1987.

FOUCAULT, M. Vigiar e Punir: a História da Violência nas Prisões. Petrópolis, RJ: Vozes, 2003.

FREIRE, P. Política e Educação. 2ae ed. São Paulo: Cortez, 1995.

Educação como Prática de Liberdade. Rio de Janeiro: Paz e terra, 1983

Pedagogia do Oprimido. Rio de Janeiro: Paz e Terra,

Conscientização: Teoria e Prática da Libertação. São Paulo: Ed. Moraes, 1980 Terra, 1979.

Educação e Mudança. 18 $8^{\underline{a}}$ ed. Rio de Janeiro: Paz e

FUNAP. Presídios e Educação: Anais do I Encontro de Monitores de Alfabetização de Adultos Presos do Estado de São Paulo. São Paulo: Funap, 1993.

GOFFMAN, E. Manicômios, Prisões e Conventos. São Paulo: Perspectiva, 2001.
MELLO, Cleyson de Moraes \& ESTEVES FRAGA, Thelma de Araújo (org.), idem, pp.1095-1096. PROCURADORIA GERAL DA REPÚBLICA DE PORTUGAL. Compilação de Normas e Princípios das Nações Unidas em matéria de prevenção do crime e da Justiça Penal. Lisboa, 1995, pp.171/17.

MIRABETE, J. F. Execução Penal: Comentário à Lei no 7210, de 117-84. 8ª ed. São Paulo: Atlas, 1997.

MIRANDA JR. H.C. Psicologia e Justiça: a Psicologia e as Práticas Judiciárias na Construção do Ideal de Justiça. In: Psicologia: Ciência e Profissão, 1998, ano 18, no 1, pp. 28-37.

PORTUGUÊS, M. R. Educação de Adultos Presos: Possibilidades e Contradições da Inserção da Educação Escolar nos Programas de Reabilitação do Sistema Penal no Estado de São Paulo. São Paulo, Dissertação de Mestrado. Faculdade de Educação da Universidade de São Paulo, 2001

SCHENEIDER, H.J. Recomensacion em Lugar de Sanción. Restablecimiento de la Paz entre el Autor, la Victima e la Sociedad. In: Kosovski, E. (org. e ed.) Vitimologia: Enfoque Interdisciplinar. Rio de Janeiro: Reproarte, 1993, pp.212-229.

RAMALHO, J.R. Mundo do Crime : a Ordem pelo Avesso. Rio de Janeiro: Graal, 1979.

SÁ, A.A. Reincidência Criminal: sob o Enfoque da Psicologia Clínica Preventiva. São Paulo: EPU, 1987.

Prisionização: um Dilema para o Cárcere e um Desafio para a Sociedade. Revista Brasileira de Ciências Criminais, ano 6 n o 21, janeiro - março de 1998, pp.117-123, 1998.

Concepção de Crime como Expressão de uma História de Conflitos: Implicações na Reintegração Social dos Condenados à Pena Privativa de Liberdade. Revista da EMESC - Escola Superior de Magistratura do Estado de Santa Catarina, ano 07, vol. 11, pp. 169178, pp. 2001.

A Recuperação dos Sentenciados e a Questão do Exame Criminológico versus Parecer das Comissões Técnicas de Classificação. Revista Brasileira de Ciências Criminais, São Paulo, ano 4, nำ13, Editora Revista dos Tribunais, 1996.

SÁ, G.R. A Prisão dos Excluídos: Origens e Reflexos sobre a Pena Privativa de Liberdade. Rio de Janeiro: Editora Diadorim, 1996.

THOMPSON, A. F. G. A Questão Penitenciária. RJ: Forense, 1980 VELHO, G. (org). Desvio e Divergência: uma Crítica da Patologia Social. Rio de Janeiro: Jorge Zahar, 1999.

ZAFFORINI, E. R. Criminologia: Aproximación desde un Margen Santa Fé de Bogotá- Colômbia: Editora Temis S.A., 1998.

\section{Referências}

